\title{
THE EVOLUTION OF THE DESIGN AND CONSTRUCTION OF MASONRY BUILDINGS IN CANADA
}

\section{Robert G. DRYSDALE $\underline{\text { email }}$}

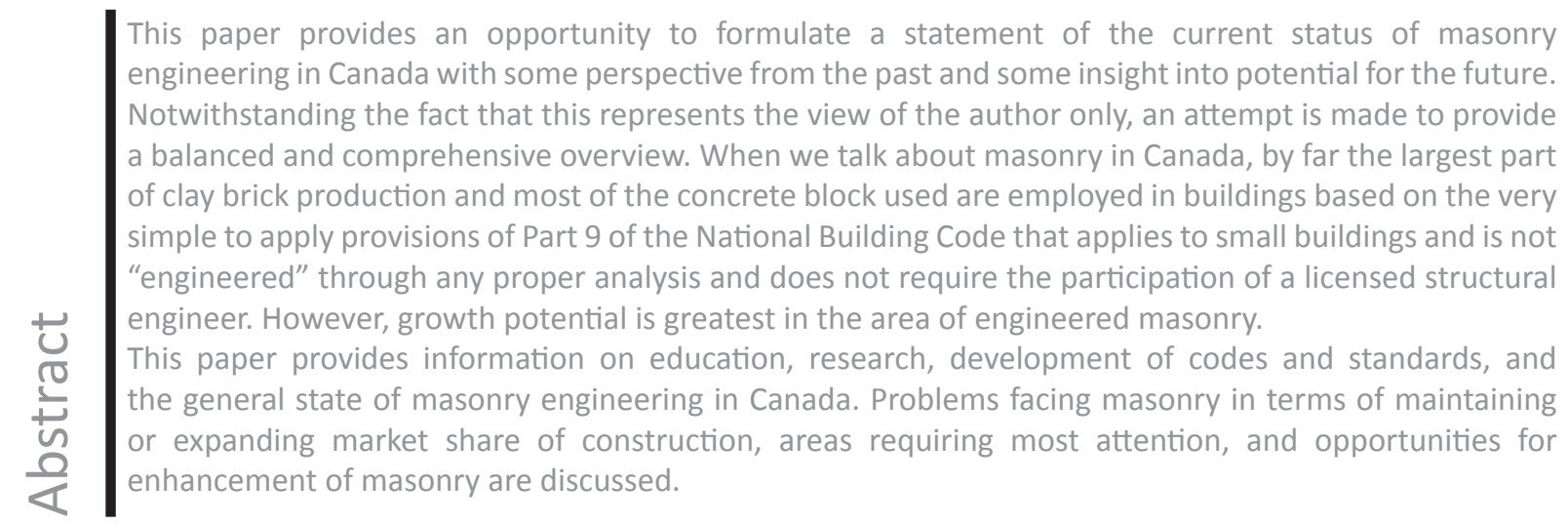

Keywords: Canada, codes, construction, design, masonry, materials, standards. 


\section{INTRODUCTION}

As a comparatively young nation, Canada's masonry heritage goes back to the early explorers and settlers who brought their building skill with them. In my own case, in 1880 my ancestors spent their first winter on the prairies in a "soddy" (a house with walls built by stacking layers of sod) followed the next year by wood construction and later, as a sign of more permanence and of being established, the homestead was upgraded to brick. This progression paralleled the general progression of early construction to masonry as the early immigrants became established in their new world. The same process was followed in construction of industrial, commercial, and institutional buildings. Natural stone bedded in lime mortar was the dominant form of masonry construction up to near the end of the nineteenth century where the parliament buildings constructed in Ottawa at the time of confederation (1867) is perhaps the most outstanding example (DRYSDALE; HAMID, 2005)
The production of portland cement and the rapid development of rational scientifically based design methods for reinforced concrete during the first part of the twentieth century along with similar progress in producing and designing high quality structural steel resulted in masonry falling far behind the technical development of these competing systems. Although masonry continued to be used extensively in small simple buildings, design was basically by tradition and "simple rules of thumb". Not only was masonry not taught in Civil Engineering programs, it was not even mentioned; this continues to be the case in the majority of degree programs in Canada. Remarkably, despite this neglect, even today, by far the largest stock of existing buildings are of masonry construction. However, increasingly over the past 50 to 60 years, the desirability of masonry has gradually decreased in the eyes of the public and of business. This is the current situation and the reason that a strong future for masonry requires strong action by the masonry industry and their partners.

\section{CODES AND STANDARDS IN CANADA}

The first masonry design code in Canada that could truly be considered as producing "engineered masonry" was incorporated into the 1965 National Building Code of Canada (NBC). This was a unified code for concrete and fired clay units (but nominally for all types of masonry units) that required analysis of forces, moments, slenderness and stresses in a working stress format with unfactored applied loads. This section of the code was modelled on British Standard CP111 (BRITISH..., 1948) and took into account Swiss research and evidence of construction of thin walled multi-storey buildings (HALLER, 1969). However, this effort was still comparatively primitive compared to similar documents for reinforced concrete and structural steel; this was so much so that the loadbearing concrete block design of the 24 storey Place Louis Riel (DRYSDALE; HAMID, 2005) built in Winnipeg, Manitoba in 1970 was reportedly somewhat daringly based on the reinforced concrete code adapted to masonry by the designer. However, rapid advances led to 17 storey unreinforced masonry buildings and a 23 storey reinforced masonry building being constructed in Hamilton, Ontario later in the 1970s using subsequent editions of the masonry part of the NBC.

As an alternative to the rational analysis introduced in 1965, the NBC also contained and continues to contain simple empirical or "rule of thumb" provisions for proportioning of masonry construction. These provisions are contained in Part 9 of the NBC dedicated to construction of small buildings ( 3 storeys or less and less than $600 \mathrm{~m}^{2}$ floor area): these provisions do not require the participation of a licensed structural engineer. Wood construction has similar provisions not requiring direct engineering input. This availability of simple, easy to use provisions has been and continues to be very important to maintaining extensive use of both of these materials and to the construction industry as it eliminates significant design cost and leads to standardized construction that builders can follow easily.

In 1970 and again in 1975, the masonry design provisions in the NBC were expanded and improved but in 1977 , similar to what had previously happened for the other major building materials, the Canadian Standards Association (CSA) took over responsibility from the National Research Council for publishing the masonry design standard. With the exception of the previously mentioned very simple empirical provisions in Part 9 of NBC, all subsequent masonry standards have been published through the auspices of that not-for-profit national organization. An important aspect of preparation of CSA Standards is that they are all prepared using volunteer 
effort with secretarial, organizational, review and publication services provided by CSA. The committee membership matrix for each standard is divided typically into 4 groups (Producers, Users, General Interest, and Regulatory Authorities) wherein the maximum size of any one group must be less than the combined minimum size of the smallest 2 groups together out of the remaining 3 groups. This balanced type of matrix helps ensure that decisions cannot be controlled by one interest group and that consensus is generally required. An additional restriction is that there can only be one voting member from any particular company or organization represented on the voting membership of the committee.

The 1977 standard combined requirements for both design and construction but by 1984, a full set of new standards had been published and referenced in the NBC. The standards listed below have since been revised on a 10-year cycle for reference in every second NBC (which is published on a 5-year cycle). The decision to adopt a 10-year cycle rather than 5 years was made based on several considerations. The first is that it takes considerable time for the design and the construction industries to become familiar with and use effectively any new standard. If changes were made at close intervals, unless these changes are small, there would never be a reasonably long period of steady state efficient use. Secondly, at the current rather gradual rate of development of new methods/products/knowledge regarding masonry construction, there are not sufficiently rapid changes for a period of 5 years to be warranted. Finally, publishing the standards involves a very high cost to the masonry industry as revenue from sales of the standards covers only a very small fraction of the actual cost. Cost to users having to replace standards at short intervals is also a barrier to high frequency of change. An addition consideration is that the pool of knowledgeable people willing to volunteer their time as committee members is too small to sustain what would be effectively a continuous process if the 5 -year cycle was adopted. The current masonry standards are:

- $\quad$ CSA S304.1 Design of Masonry Structures (CANADIAN..., 2004e);

- $\quad$ CSA A371 Masonry Construction for Buildings (CANADIAN..., 2004d);

- $\quad$ CSA A370 Connectors for Masonry (CANADIAN..., 2004c);

- $\quad$ CSA A179 Mortar and Grout for Unit Masonry (CANADIAN..., 2004b);

- $\quad$ CSA A165 Standards on Concrete Masonry Units (CANADIAN..., 2004a);

- $\quad$ CSA A82 Fired Masonry Brick Made from Clay or Shale (CANADIAN..., 2006).

With the separation of construction from design, a sometimes seen specification such as "construction shall conform to the requirements of CSA S304" is avoided and it is clear that contractors are not required to know and follow design requirements; these are strictly the responsibility of the designer. On the other hand, whereas contractors must know and follow the requirements of CSA A371 (CANADIAN..., 2004d), designers also must be familiar with these provisions for the purposes of good design and to specify which option (other than the default) to follow when alternatives are presented in the standard. An example of a previous problem now avoided is vertical movement joints: If not otherwise detailed, the contractor would follow the A371 provisions but location and type of movement joint must be shown or specified by the designer in the contract documents. A knowledgeable contractor might question the absence of vertical movement joints but would not independently put some in.

Another feature of CSA S304 (CANADIAN..., 2004e) is that Engineered Masonry Design comprises the main part of the standard. However, provisions for Empirical Design for Unreinforced Masonry were included in an Annex. The empirical design provisions are much more extensive and more rational than the very simple provisions in Part 9 of the NBC and, therefore, are permitted to be used for design of unreinforced masonry for a much larger range of buildings than in Part 9. Limits are mainly associated with maximum wind pressure and seismic zone. Efforts have been made to avoid creating situations where structures proportioned using Empirical Design are more economical that what is achieved using the much more comprehensive analyses associated with Engineered Design. However, in keeping the empirical design provisions simple yet not overly conservative, it is difficult to maintain uniform levels of safety for all possible conditions. In the soon to be published 2014 edition of CSA S304, after some reworking of provisions, Empirical Design is again slated to be included as a convenience to designers even though the range of applications follows the trend since 1984 of becoming more restrictive. It is important to know that empirically designed loadbearing components cannot be included in buildings designed in accordance with Engineered Masonry Design.

In 1984, although limit states design provisions had been developed, the committee decided to include only design based on the working stress method. In 1994, a full limit states method was substituted but, even though no further work was done on working stress, use of the 1984 edition was permitted as an alternative for the next 10 years by also referencing this older standard in the NBC. The idea was to make it as easy as possible for designers to adopt engineered masonry as their principal design tool. 
Except for its simplified use in Empirical Design, working stress (allowable stress) methods were no longer permitted following adoption of the 2005 NBC. Analyses of comparable designs, consistently confirms that the limit states approach results in more economical use of materials and more consistent levels of safety.

To avoid having an extra standard, there are elements of both design and construction in CSA A370 (CANADIAN..., 2004c) wherein connectors is the generic term for ties, anchors, and fasteners. This standard is referenced in both the design and the construction standards and an attempt is made to indicate when design decisions are required to be made and shown in the contract documents. The 3 materials standards (A179 (CANADIAN..., 2004b), A165 (CANADIAN..., 2004a), and A82 (CANADIAN..., 2006)) set out the quality and testing requirements that must be met by producers for mortar, grout, concrete masonry units, and fired clay units. Since these standards are referenced both in the design and construction standards as well as job specifications, the intent is that their content should be understood by all parties.

Because standards are costly to prepare and number of copies sold is relatively small, use is made of standards in other countries to provide more complete coverage of the topics relevant to masonry construction. ASTM standards from the USA are the principal source as they generally reflect practices most closely resembling Canadian practice and are readily available. For instance, ASTM C73 is used for calcium silicate units as this type of unit is used in only a very small fraction of masonry construction in Canada. Specific editions of the standards are reviewed and referenced. Newer editions are review as they become available and, in some cases where changes justify the cost, these are referenced by issuing an amendment to the referencing standard. Similarly, errors can be corrected and significant advances can be incorporated in standards by issuing amendments but generally this is avoided if possible so that tracking of changes by users is not a complication.

\section{MASONRY EDUCATION IN CANADA}

It is fundamental to having well engineered masonry that there exists a large group of practicing structural engineers who have sufficient knowledge and experience to design efficiently and to produce designs that make effective and efficient use of masonry materials. Prior to the mid-1970s, engineered masonry design was not taught at any Canadian University, and except for a very few engineers with some international masonry training, those designing masonry were self-taught without the aid of textbooks, design guides, etc. As a result, the level of capability was low with most design following empirical rules. To the extent that engineered masonry was used, it tended to be conservatively applied through uncertainty and caution on the part of the designer.

During the mid and late 1970s, several Engineering schools developed courses on masonry design ranging from 6 week components of other courses to 12 or 13 week stand alone courses; some were at the graduate level where fewer curriculum limitations made it easier to fit them in whereas some Universities had senior undergraduate courses or both graduate and undergraduate courses. To try to encourage the development of masonry education of engineering undergraduates in Canadian Universities, industry sponsored 4-day long Professors Workshops were held at McMaster University in 1975, 1990, and 1993. These were very well attended with typically all (26) of the
English speaking Universities and a couple of the French speaking Universities represented (usually by 2 faculty members). However, with a couple of exceptions, these workshops did not produce major change: a couple of Universities added a couple of weeks of masonry in an existing course and one, with the lecturing help of the masonry industry, developed a full term course.

In the late 1970s and early 1980s, what was more successful was the provision of small research grants to encourage masonry research with the hope that, beyond the benefit of the research results themselves, participation by faculty members would increase their motivation to undertake the significantly difficult task of gaining approval for including masonry in their departments' curricula and of preparing the course material. This initiative proved to be quite successful with virtually all of the participating schools developing some formal form of masonry design instruction; this included 10 schools by the mid to late 1980s.

Changing leadership and focus in the masonry industry, a late 1980s boom period in construction followed by recession, and retirements of participating faculty members were among the factors leading to a gradual erosion of the gains made so that by the late 1990s - early 2000s, education (and research) was much as it had been in the late 1970s in terms of number of Universities 
involved but, many more undergraduates were being trained at those remaining schools and research activity was quite high. Endowed research chairs at McMaster University by Ontario Masonry Contractors Association and significant funding at University of Calgary were positive unprecedented industry initiatives of the time. With the formation of the Canada Masonry Design Centre, industry began the process of directly educating current designers by offering rigorous 6-week courses. They also became a resource to help designers correctly apply design provisions and help with construction related problem solving.

Since about the mid-2000s, the concrete block industry has re-organized and developed a funding scheme that has made available several million dollars for research funding. Together with the masonry contractor associations from Ontario and provinces west through to British Columbia, they have succeeded in again managing the expansion of masonry research and education back to the high levels of the late 1980s. In this case, the typical approach has been to identify new younger members of faculty who show promise of being able to contribute to masonry research and education at their institutions. In addition to providing research funding (as well as materials and mason time), these participants have been supported in endeavours to obtain additional government, university, and private sector support. Also, although many of the new researchers initially had minimal background in masonry, they were invited to join standards committees, initially as associate members but graduating to full voting membership as their abilities to contribute increased.
It is likely that support cost limitations and the logistical limitations of managing a large funding enterprise mean that the above outreach to Universities cannot be extended to all Universities on a continuous basis. However, with about half of the Universities involved in masonry education in the near future, it is to be hoped that the remainder will understand the need to provide masonry education for their own students and will introduce their own courses. They should also begin to compete with others for industry research funding.

As for competing structural systems, wood has achieved some success in gaining access to the classroom without there being corresponding wood researchers at those institutions. Although not universal, this activity was seen locally as the right thing to do for the benefit of the graduating students. Reinforced concrete and steel design are taught in all institutions without those industries having ever contributed substantial amounts of research funding. However, it is an historical fact that educators (and subsequent accreditation teams) have always recognized the graduates' need for those components of education whereas masonry was not seen in the same way. Despite evident dissatisfaction with this inequality, the masonry industry has (I think wisely) decided that trying to force or convince Universities to include masonry would not provide timely results if any. It is much more effective to provide direct encouragement and support to individuals who will then be the agents for including masonry in the departmental curricula. If the industry can "stay the course", the hope is that including masonry education will be normal and will join reinforced concrete and steel as essential parts of the education of the Canadian structural designers of the future.

\section{MASONRY RESEARCH IN CANADA}

In the 1970s-1980s period of growth of masonry research in Canada coinciding with organization of the first 5 Canadian Masonry Symposiums (1976, Calgary; 1980, Ottawa; 1983, Edmonton; 1986, Fredericton; and 1989, Vancouver), two observations were:

- $\quad$ None of the early masonry researchers had progressed from an original masonry research background; most had originally researched reinforced concrete. Although several $\mathrm{Ph}$. D. graduates from Canadian schools were pursuing masonry research elsewhere in the world, none had been employed on a permanent basis at a Canadian University;

- $\quad$ Even with 10 or 12 active masonry research teams, the need for masonry research to supplement existing knowledge for codes and standards development far exceeded present or anticipated future home-grown research capability; it was not only wise but necessary that research from around the world be utilised in the development of Canadian standards. The masonry industry accepted this premise and has provided strong support for the Canadian Masonry Symposia as part of the overall attempt to internationalize our considerations.

In the 2000s redevelopment of masonry research in a larger number of institutions, one factor has changed in that several of the new masonry researchers already have masonry research experience through Ph. D. programs in Canada and abroad. Others again come mainly from a reinforced concrete background 
but are being specifically identified and encouraged to move their research toward masonry. So far this has been quite successful and several researchers without previous masonry experience have begun to provide useful research results and contribute in standards preparation. The industrial financial support, genuine interest and attention by the supporting groups, and the opportunity for the research results to have immediate impact are attractive factors for all researchers but particularly for those at the beginnings of their careers.

A strategy that many of the new researchers are learning is to take advantage of government incentives that encourage industry-university collaboration wherein government funding to match industry contributions enables the researchers to be much more productive. In many cases, this funding can be added to the annual Discovery Grants provided in 5-year periods by the Natural Sciences and Engineering Research Council based on a peer review system. Although typically not large, the Discovery Grants provide continuity of funding so that a "feast or famine" scenario is avoided and researchers can plan and carry out long term research. Nowadays, masonry researchers can maintain quite high levels of support by augmenting this base support through competing for other more topic focused government and private research projects. This beneficial funding situation appears to be fairly unique among international researchers.

In the Canadian context, several of the most critically important areas of ongoing and needed research are discussed below:

DESIGN FOR SEISMIC FORCES. The highly publicized poor performance of unreinforced masonry during earthquakes around the world has created a very negative view amongst those responsible for National Building Code's seismic provisions regarding the capacity of all forms of masonry to resist the effects of seismic loading. This is despite the fact that the recorded poor performances have been almost entirely for unreinforced masonry and much of that not of good design and/or good quality. The result is that current provisions for masonry lead to significantly higher minimum lateral design loads than are calculated for competing structural systems. In Canada, separate ductility and overstrength related force modification factors are used in defining the ratio of the equivalent static lateral earthquake design force to the elastic load. The maximum product of these values for moderately ductile reinforced masonry shear wall construction is $(2.0 \times 1.5=3.0)$ compared to $(3.5 \times 1.6=5.6)$ for ductile reinforced concrete shear walls. This means that a reinforced masonry building must be designed for $(5.6 / 3.0)=1.87$ times as much lateral load as for a similar reinforced concrete building.
Seismic research on performance of reinforced concrete block shear walls at McMaster University (SHEDID; DRYSDALE; EL-DAKHAKHNI, 2008) and elsewhere clearly shows that much larger ductilities are present than are given credit even for conditions with no special detailing. Earthquake researchers have currently drafted changes to CSA S304 and NBC for 6 types of masonry SFRS as follows:

- $\quad$ Special Shear Walls $\left(R_{d}=4.0, R_{o}=1.5\right)$ : Test results show very high ductility for walls having boundary elements to create confined ends either within the thickness of the wall or as columns built into the ends of the wall;

- $\quad$ Ductile Shear Walls $\left(R_{d}=3.0, R_{o}=1.5\right)$ : Bond beam and vertical reinforcing spacing limited to $1.2 \mathrm{~m}$ with seismic hazard related building height limits as well as limits on unsupported wall height, length of the compression zone, and splice detailing;

- $\quad$ Moderately Ductile Shear Walls $\left(R_{d}=2.0\right.$, $R_{o}=1.5$ ): For walls with height/length ratio less than 2, partial grouting is permitted in the plastic hinge region but level of axial load is limited for the highest 2 seismic hazard indices. This provides a category similar to confined masonry used in South America where either flexural or shear types of failure can control capacity and ductile behaviour. Otherwise, for fully grouted plastic hinging regions, there are some simple detailing requirements and reduced height limits down to $40 \mathrm{~m}$ for the highest seismic hazard index;

- $\quad$ Conventional Construction $\left(R_{d}=1.5\right.$, $\left.R_{o}=1.5\right)$ : This category contains 2 options:

- Shear walls. Building heights decreasing from no limit to $15 \mathrm{~m}$ with increasing seismic hazard index, spacing of vertical reinforcing of $2.4 \mathrm{~m}$ allowed in 2 lowest indices but limited to $1.2 \mathrm{~m}$ where more severe earthquakes are expected;

- Moment-Resistant Frames. This is not permitted in the highest 2 seismic hazard index categories and has a height limit of $30 \mathrm{~m}$ in the second lowest category.

- $\quad$ Unreinforced Masonry $\left(R_{d}=1.0, R_{o}=1.0\right)$ : This involves height limits of 30 and $15 \mathrm{~m}$ in the lower 2 seismic hazard categories and is not allowed in the upper 2 categories;

- $\quad$ Other Masonry SFRS(s) not Listed above $\left(R_{d}=1.0, R_{o}=1.0\right)$ : Buildings up to $15 \mathrm{~m}$ height are allowed. Infilled frames could be an example of type of construction.

DESIGN OF MASONRY INFILL IN FRAMES. Provisions for infill design are being worked on to try to provide realistic models for analysis. A problem in the equivalent strut approach is to devise a strut that can be used both to predict elastic displacements as well as strength. In addition, as indicated above, 
information on seismic performance is quite limited and does not include expected benefit when the infill is reinforced and/or positively attached to the frame.

COMPRESSIVE STRENGTH OF MASONRY. This most fundamental property of masonry is one that is yet to be adequately dealt with. For both research and design, it is known that test results from 2-block high prisms significantly overestimate the strength observed in structural members; prisms with height to thickness ratio of 4 provide a much closer value that is typically about $15 \%$ lower than the 2-block high value. However, since 2-block high prisms are much more feasible for quality assurance, the variable effects of hollow versus grouted solid and strengths of the individual materials hinder the conversion of 2-block prism results into effective strength.

Added to the above difficulty is the fact that compressive strengths parallel to the bed joints are significantly different (generally found to be lower) than the usually referred to strengths normal to the bed joints. This is important for beams, horizontally spanning walls, and for strut design of infill walls. Again the effects of hollow versus solidly grouted are significant as is the degree to which the grout is continuous in the direction of the compressive force: the actual and relative strengths of the individual materials also affect the strength. Study of this subject is complicated by the fact that prisms made using block of equal strength obtained from a variety of manufacturers can have average strengths that differ by $20 \%$. For the 2014 series of standards, some modifications will be made but it is expected that this will remain a topic of research at least for the next cycle of standards.

FLEXURAL WALL PANELS. Originating with British standards in the 1970s, design of unreinforced wall panels for out-of-plane loading has incorporated methods that rely on plastic behaviour expressed in a yield line or similar type of analysis. The use of a plastic method of analysis to model a brittle behaviour means that the resulting design is empirically based. In CSA S304 (CANADIAN..., 2004e), this analysis has been modified to a Failure Line Method that eliminates the flexural capacity along the line of the first crack to form. It is treated as a hinge that is not part of the load resisting mechanism. This difference is justified by test results which show that half panels geometrically identical to the halves of panels defined on each side of a first horizontal crack have identical capacity to resist lateral load. Moment resistance along supports provided by any continuity of wall panels past the supports is not included in CSA S304. As a result of these differences, the CSA version is more conservative than the original British approach.
Despite a natural discomfort with the empirical basis for the Failure Line Method, the significant body of test results from around the world support the validity of the result. We are currently evaluating extension of this approach to include the effects of openings in wall panels.

SLENDER WALLS. Moment magnifier methods to account for slenderness effects in out-of-plane bending of walls have been included in past editions of CSA S304. To accommodate very slender walls that may buckle prior to reaching section failure under increasing bending moment, somewhat conservative estimates of effective flexural stiffness are used. In the long term, research is needed to determine if a more refined method of calculating this value for less slender walls is warranted.

EFFECTIVE WIDTH OF COMPRESSION ZONE. For walls with large spacing of vertical reinforcing bars, similar to flanges on a t-beam, it is expected that there should be some limit to the horizontal distance away from the bar along the wall that can be considered to be effective as part of the compression zone in the analysis of the cross-section under combined axial load and bending moment. In the MSJC code and CSA S304 (CANADIAN..., 2004e), values of 6 and 4 times the wall thickness are specified, respectively. Clearly both cannot be correct and, in reviewing he original research, there should be doubt as to whether there has ever been adequate evidence to justify a value. Other factors such as distance from the top or bottom of the wall and extent of grouting are also likely to have an effect. This may be a research topic for the next cycle of standards. TENSILE STRENGTH OF MASONRY. Whereas compressive capacity has undergone a safety index type of statistical analysis to develop material resistance factors, tensile strength design provisions have simply been calibrated to give similar designs as produced using previous editions of CSA S304. In a statistical evaluation, the extremely high variability of recorded tensile strengths invariably leads to recommendations for significantly lower design tensile strength. To date, except for wall failures during construction due to wind loading on inadequately braced walls, there have not been sufficient reported problems to justify a claim that the current design approach is unsafe. Significant reductions in design values for tensile strength would have large impact on design of unreinforced masonry and likely lead to reinforcing being required much more often.

RETROFIT OF MASONRY. Damaged masonry, masonry that has deteriorated over time, and masonry that needs to be strengthened to satisfy required levels of safety involve somewhat different construction methods and ways of thinking compared to new construction. Adding to this the desire for 
conservation of historic structures takes most designers and builders outside of their comfort zones. In the latter case, much of what is considered as conventional wisdom is anecdotal in nature and not supported by rigorous scientific investigation. As more and more of masonry work falls into this general retrofit area, more research will be needed to better standardize the process and to provide better guidance for all concerned.

GENERAL. There is hardly an area of masonry research that could not benefit from additional research. Bond and anchorage of reinforcement, shear capacity of elements, prediction of deflections, elastic properties, tie loads, environmental loading are examples that come effortlessly to mind. For industry support, it is mainly a matter of establishing priorities but even here, as mentioned previously, any research is good research if it gets a new researcher interested in and familiar with masonry as that has proven to be the most successful means for developing educational programs in Universities.

\section{CONCLUSION}

In Canada, the masonry industry has been uniquely proactive in encouraging masonry research and education. They see it as being in their self-interest as part of the way to maintain and hopefully expand their share of the construction market. Similarly, availability of up-to-date, rational, and easy to understand codes and standards are seen as being important as is the availability of design aids and other sources of assistance and information. Given the cyclical nature of economies and the resulting large variations in building activity, maintaining a reasonably consistent and well planned path forward over the decades is a challenge. I am optimistic that masonry in Canada is on a path toward a healthy future but caution that sometimes it takes only a few diversions or lapses in attention to undo what has been painstakingly created.

\section{REFERENCES}

BRITISH STANDARDS INSTITUTION - BS. CP 111: Structural recommendations for loadbearing walls. London: British Standards Institution, 1948.

CANADIAN STANDARDS ASSOCIATION - CSA. CSA A165: CSA Standards on concrete Masonry Units. Mississauga: CSA, 2004a.

CANADIAN STANDARDS ASSOCIATION - CSA. CSA A179: Mortar and Grout for Unit Masonry. Mississauga: CSA, 2004b.

CANADIAN STANDARDS ASSOCIATION - CSA. CSA A370: Connectors for Masonry. Mississauga: CSA, 2004c.

CANADIAN STANDARDS ASSOCIATION - CSA. CSA A371: Masonry Construction for Buildings. Mississauga: CSA, 2004d.

CANADIAN STANDARDS ASSOCIATION - CSA. CSA S304.1: Design of Masonry Structures. Mississauga: CSA, 2004e.

CANADIAN STANDARDS ASSOCIATION - CSA. CSA A82: Fired Masonry Brick Made from Clay or Shale. Mississauga: CSA, 2006.

DRYSDALE, R. G.; HAMID, A. A. Masonry Structures: Behaviour and Design. Mississauga: Canadian Edition, Canada Masonry Design Centre, 2005.

HALLER, P. Load Capacity of Brick Masonry. In: JOHNSON, F. (Ed.). Designing, Engineering and Construction with Masonry Products. Houston: Gulf Publishing, 1969.

SHEDID, M. T.; DRYSDALE, R. G.; EL-DAKHAKHNI, W. W. Behavior of Fully Grouted ReinforcedConcrete Masonry Shear Walls Failing In Flexure: Experimental Results. Journal of Structural Engineering, v. 134, n. 11, p. 1754-1767, 2008. http://dx.doi.org/10.1061/(ASCE)0733-9445(2008)134:11(1754) 


\section{ACKNOWLEDGEMENTS}

In this paper, there has not been space to review or acknowledge the major individual contributions of researchers and members of the masonry industry in Canada. Some who have had great presence and impact in both the research end and the industry end are now retired or no longer with us. Personally, it is the interaction with the individuals that has helped to make my own career interesting to me since beginning my own involvement with masonry in 1974. It still provides the incentive to continue although at a slower pace.

\section{DADOS DOS AUTORES}

(i) Ph. D, P. Eng., Professor Emeritus, McMaster University, Hamilton, Ontario, drysdale@mcmaster.ca 